\title{
Long-Chain Hydrocarbons (C21, C24, and C31) Released by Bacillus sp. MH778713 Break Dormancy of Mesquite Seeds Subjected to Chromium Stress
}

OPEN ACCESS

Edited by:

Robin Tecon,

ETH Zürich, Switzerland

Reviewed by:

Anca Delgado,

Arizona State University, United States

Marie Chantal Lemfack,

University of Rostock, Germany

${ }^{*}$ Correspondence: Antonino Baez antonino.baez@correo.buap.mx

Specialty section:

This article was submitted to Terrestrial Microbiology, a section of the journal Frontiers in Microbiology

Received: 10 September 2019 Accepted: 30 March 2020 Published: 24 April 2020

Citation: Ramírez V, Munive J-A, Cortes $L$, Muñoz-Rojas J, Portillo $R$ and Baez $A$ (2020) Long-Chain Hydrocarbons (C21, C24, and C31) Released by

Bacillus sp. MH778713 Break Dormancy of Mesquite Seeds Subjected to Chromium Stress. Front. Microbiol. 11:741. doi: 10.3389/fmicb.2020.00741
Verónica Ramírez¹, José-Antonio Munive ${ }^{1}$, Luis Cortes², Jesús Muñoz-Rojas', Roberto Portillo² and Antonino Baez ${ }^{1 *}$

${ }^{1}$ Centro de Investigaciones en Ciencias Microbiológicas, Instituto de Ciencias, Benemérita Universidad Autónoma de Puebla, Puebla, Mexico, ${ }^{2}$ Facultad de Ciencias Químicas, Benemérita Universidad Autónoma de Puebla, Puebla, Mexico

Volatile organic compounds (VOCs) produced by rhizobacteria have been proven to stimulate plant growth during germination and seedling stages. However, the modulating effect of bacterial volatiles on the germination of seeds subjected to heavy metal stress is scarcely studied. In this work, the ability of volatiles released by Bacillus sp. MH778713 to induce seed dormancy breakage in Prosopis laevigata and Arabidopsis thaliana seeds were examined. The minimal inhibitory concentration of chromium $(\mathrm{Cr}) \mathrm{VI}$ that prevents seed germination of $P$. laevigata and $A$. thaliana on water-Cr-agar plates was 2500 and $100 \mathrm{mg} \mathrm{L}^{-1}$, respectively. Remarkably, partitioned Petri-dish co-cultivation of Bacillus sp. MH778713 and plant seeds under Cr-stress showed the beneficial effect of volatiles emitted by Bacillus sp. MH778713, helping plant seeds to overcome Cr-stress. Among the metabolites emitted by Bacillus sp. MH778713, octadecane, heneicosane, 2,4-di-tert-butylphenol, hexadecane, eicosane, octacosane, and tetratriacontane were the most abundant. To confirm that these long-chain compounds produced by Bacillus sp. MH778713 could be responsible for the seed dormancy breakage, high pure organic compounds (2,4-di-tert-butylphenol, heneicosane, hentriacontane, and tetracosane) were used directly in germination assays of $P$. laevigata and $A$. thaliana seeds instead of volatiles emitted by Bacillus sp. MH778713. All organic compounds allowed Prosopis and Arabidopsis seeds to overcome Cr-toxicity and germinate. The results of this study provide new insight into the role of long-chain bacterial compounds produced by Bacillus sp. MH778713 as triggers of seed abiotic stress tolerance, surmounting chromium stress and stimulating seedling development.

Keywords: bacterial volatile, seed dormancy, chromium stress, growth promotion, Prosopis laevigata

\section{INTRODUCTION}

Plant growth-promoting rhizobacteria (PGPR) are beneficial plant symbionts capable of providing plants with improved water and nutrient uptake (Vacheron et al., 2013; Backer et al., 2018). Rhizobacteria are intimately associated with the root system of the plants and can affect the growth and fitness of plants by modulating nutrient uptake, inducing systemic resistance, and tolerance to 
abiotic and biotic stress (Bitas et al., 2013; Backer et al., 2018). PGPR can produce auxins, cytokinins, and gibberellins that regulate plant growth and development. Furthermore, each rhizobacterial species produce a specific blend of volatile organic compounds (VOCs) with important roles in plant biology and bacterial life cycle (Ryu et al., 2003; Sharifi and Ryu, 2018).

Bacterial volatiles can modulate root architecture, iron uptake, sodium and auxin homeostasis in plants (Zhang et al., 2007; Gutierrez-Luna et al., 2010; Liu and Zhang, 2015). Thus, saltstressed plants treated with Bacillus amyloliquefaciens VOCs show greater $\mathrm{Na}^{+}$-stress tolerance than control plants (Zhang et al., 2008). Similarly, drought-stressed plants exposed to B. subtilis GB03 VOCs were more tolerant than plants without VOCs treatment due to the accumulation of osmoprotectants such as choline and glycine (Zhang et al., 2010; Liu and Zhang, 2015). The volatile blend release by Bacillus subtilis GB03 can also induce systemic resistance in Arabidopsis against Erwinia carotovora (Ryu et al., 2004). To date, the demonstrated efficacy of VOCs in enhancing plant fitness and tolerance to salinity, drought, iron deficiency, and sulfur starvation stress suggest that bacterial volatiles might help plants to tolerate other abiotic stresses, but their effectiveness should be confirmed for each stress condition.

Seed dormancy and germination are complex processes regulated mainly by the plant hormones gibberellins (GAs) and abscisic acid (ABA). Environmental and endogenous factors might control the abundance of signaling molecules which determine the $\mathrm{ABA} / \mathrm{GAs}$ ratio, thus elevated $\mathrm{ABA}$ concentration within seeds triggers seed dormancy while high GAs level induces germination (Bailly et al., 2008; Graeber et al., 2012; Li et al., 2018). There are different definitions and classifications of seed dormancy; a delay or fail to germinate under favorable conditions is a generally accepted definition (Arc et al., 2013). Several abiotic stresses like salinity, drought, cold, and exposure to heavy metal can induce ABA biosynthesis and seed dormancy (Vishal and Kumar, 2018). Indeed, arsenic and vanadium up-regulate $\mathrm{ABA}$ biosynthesis genes of rice roots while cadmium increases endogenous ABA levels (Bücker-Neto et al., 2017). Germination of wheat, cucumber, and chickpea seeds decreases by exposure to copper $\left(\mathrm{Cu}^{2+}\right)$, zinc $\left(\mathrm{Zn}^{2+}\right)$ or lead $(\mathrm{Pb})$ whereas abscisic acid content increase; suggesting that $\mathrm{ABA}$ plays an important role not only on seed germination but also in stress response (Munzuroğlu et al., 2008; Wang et al., 2014; Bücker-Neto et al., 2017).

Chromium (Cr) is a non-essential and toxic element to plants and animals. The most ubiquitous oxidation states of $\mathrm{Cr}$ in nature are trivalent (Cr III) and hexavalent (Cr VI) chromium; being $\mathrm{Cr}(\mathrm{VI})$ the most phytotoxic (Panda and Choudhury, 2005). Chromium(VI) at concentrations ranged $50-100 \mathrm{mg} \mathrm{kg}^{-1}$ soil are toxic for most plants affecting germination rate, chlorophyll content, and most of the growth parameters (Akinci and Akinci, 2010; Jain et al., 2016; Amin et al., 2019). For plants growing in a nutrient solution, $10-25 \mathrm{mg} \mathrm{L}^{-1} \mathrm{Cr}$ VI is detrimental for plant development (Dube et al., 2003; Ramírez et al., 2019). Nonetheless, Prosopis plants can tolerate, translocate, and hyper accumulate heavy metals, including $\mathrm{Pb}$, As and $\mathrm{Cr}^{6+}$ (Aldrich et al., 2003, 2007; Jayaram and Prasad, 2009). We reported that Prosopis trees grown in polluted wildlife habitats are highly tolerant of $\mathrm{Cr}$ (VI), in part, by their interaction with the endophytic chromium hyper-tolerant Bacillus sp. MH778713 (Ramírez et al., 2019). Bacillus sp. MH778713 was isolated from Prosopis laevigata nodules. This Bacillus strain tolerates up to $15000 \mathrm{mg} / \mathrm{L} \mathrm{Cr}(\mathrm{VI})$, bioaccumulates up to $100 \mathrm{mg} \mathrm{Cr}$ (VI)/g of cells and promotes the development of Cr-stressed $P$. laevigata seedlings growing in hydroponic systems. Other $\mathrm{Cr}-$ resistant bacteria with lower tolerance (up to $780 \mathrm{mg} / \mathrm{L} \mathrm{Cr}$ ), including Bacillus genera, also promote the growth of $\mathrm{Cr}$-stressed plants suggesting that PGPR help plants to reduce metal-induced oxidative damage (Bruno et al., 2020; Din et al., 2020; Shreya et al., 2020). Cr-tolerant bacteria with PGPR features ameliorate Cr-toxicity on plants through reduction of $\mathrm{Cr}(\mathrm{VI})$ to $\mathrm{Cr}(\mathrm{III})$ to stabilize Cr, increasing antioxidant activities of plants, reducing lipid peroxidation and removing $\mathrm{Cr}$ from soil (Purwanti et al., 2017; Bruno et al., 2020; Din et al., 2020). In this paper an elevated $\mathrm{Cr}(\mathrm{VI})$ concentration $\left(2500 \mathrm{mg} \mathrm{L}^{-1}\right)$ was required to prevent germination of imbibed seeds of Prosopis, highlighting the tolerance of Prosopis to heavy metals. Only seeds exposed to Bacillus sp. MH778713 volatiles were able to germinate in the presence of $2500 \mathrm{mg} \mathrm{L}^{-1} \mathrm{Cr}(\mathrm{VI})$. Long-chain alkanes released by Bacillus sp. MH778713 were found to help seeds to overcome dormancy, the potential role of these compounds in response to chromium stress will be discussed.

\section{MATERIALS AND METHODS}

\section{Bacteria and Seed Preparation}

Bacillus sp. MH778713, an isolate from $P$. laevigata nodules (Ramírez et al., 2019), and Escherichia coli BL21(DE3) were streaked onto yeast-extract mannitol agar (YMA) plates and incubated for $24 \mathrm{~h}$ in darkness at $28^{\circ} \mathrm{C}$. For long-term storage, bacterial strains were kept at $-80^{\circ} \mathrm{C}$ in yeast-extract mannitol broth with $20 \%(\mathrm{v} / \mathrm{v})$ glycerol. Prosopis laevigata seeds were surface-sterilized by rinsing with distilled water and then soaking in concentrated sulfuric acid (98\%) for $20 \mathrm{~min}$, followed by rinsing 3-4 times in sterile distilled water. Arabidopsis thaliana ecotype Columbia (Col-0) seeds were prepared by treating them with $2 \%$ Tween-20 for $1 \mathrm{~min}$, washed five times with sterile distilled water and placed on Petri dishes containing water agar $(0.75 \% \mathrm{w} / \mathrm{v})$. All chemicals including heneicosane, hentriacontane, 2,4-di-tert-butyl phenol, and tetracosane were purchased from Sigma Aldrich.

\section{Determination of Minimum Inhibitory Concentration (MIC) of Chromium to Stop Germination of Prosopis laevigata and Arabidopsis thaliana}

To determine the minimal amount of $\mathrm{Cr}(\mathrm{VI})$ that stop seed germination of Prosopis laevigata, increasing concentrations of $100 \mathrm{mg} \mathrm{L}^{-1}$ chromium $(100,200,300,400$ up to $2500 \mathrm{mg}$ $\mathrm{L}^{-1}$ ) were assayed. For Arabidopsis thaliana ecotype Col-0 increasing concentrations of $10 \mathrm{mg} \mathrm{L}^{-1} \mathrm{Cr}(\mathrm{VI})(10,20,30$, 40 up to $100 \mathrm{mg} \mathrm{L}^{-1}$ ) were assayed. Higher concentrations of chromium were not assayed because $P$. laevigata and A. thaliana 
seeds did not germinate with 2500 and $100 \mathrm{mg} \mathrm{L}^{-1}$ of $\mathrm{Cr}(\mathrm{VI})$, although they did germinate with 2400 and $90 \mathrm{mg}$ $\mathrm{L}^{-1}$, respectively. Surface-sterilized Prosopis or Arabidopsis seeds were placed onto partitioned plates containing water-agar $(0.75 \% \mathrm{w} / \mathrm{v})$ added with concentrations of $\mathrm{K}_{2} \mathrm{CrO}_{4}$ described above. Petri plates with seeds were incubated at $28^{\circ} \mathrm{C}$ for 24 and $72 \mathrm{~h}$ in dark for the germination test of Prosopis and Arabidopsis. After germination, Prosopis and Arabidopsis seedling were incubated two more days for complete radicle development. The minimum inhibitory concentration assay was done in quintuplet, each experiment was repeated at least three times.

\section{Effect of Volatiles Released by Bacillus sp. MH778713 on Germination of Cr-Stressed Seeds}

To determine whether the blend of volatiles emitted by Bacillus sp. MH778713 could help Prosopis or Arabidopsis seeds to overcome Cr-stress, co-cultivation of Bacillus sp. MH778713 and Prosopis/Arabidopsis seed in a partitioned Petri dishes were carried out. Partitioned Petri dishes prevents physical contact between Bacillus and seeds. Thus, $10 \mu \mathrm{l}$ of Bacillus sp. MH778713 $\left(1 \times 10^{10} \mathrm{CFU} / \mathrm{ml}\right)$ was inoculated on Yeast extract Mannitol Agar (YMA) medium on one side of the partitioned plate and Prosopis seed was placed on the Cr-water agar [2500 $\mathrm{mg} \mathrm{L}^{-1}$ of $\mathrm{Cr}(\mathrm{VI}), 0.75 \% \mathrm{w} / \mathrm{v}$ agar] medium on the other side of the plate. Similarly, Arabidopsis seeds were germinated on partitioned plates with Cr-water agar medium but with only $100 \mathrm{mg} \mathrm{L}^{-1}$ of $\mathrm{Cr}(\mathrm{VI})$. After inoculation, Petri dishes containing seeds were covered and sealed with parafilm to minimize volatiles leaking. Treated plates were incubated at $28^{\circ} \mathrm{C}$ for 24 and $72 \mathrm{~h}$ in the dark for seed germination test of Prosopis and Arabidopsis, respectively. Pictures of Figure 1 were taken 2 days after germination to let seedling reach a greater development. Partitioned Petri dishes with Prosopis or Arabidopsis seeds on Cr-water agar medium and YMA without Bacillus or with Escherichia coli BL21(DE3) were used as negative controls. Germination assay of Cr-stressed seeds in the presence and absence of Bacillus sp. MH778713 volatiles was performed in quintuplet, each being repeated at least three times.

\section{Analysis of Metabolites Released by Bacillus sp. MH778713}

To determine the metabolites produced by Bacillus sp. MH778713, co-cultivations of Bacillus and Prosopis seeds in partitioned Petri dishes were carried out as described above but plates were incubated for 24 and $48 \mathrm{~h}$. To do that, sealed Petri plates containing the Bacillus culture were incubated and then opened at $24 \mathrm{~h}$ to extract the compounds released by the bacterium while other plates were opened at $48 \mathrm{~h}$. To extract the compounds released by Bacillus sp. MH778713, $3 \mathrm{ml}$ of benzene was added into the compartment of the Petri dishes containing the Bacillus culture, the Petri dishes were gently shaken for $1 \mathrm{~min}$ and benzene was collected into microtubes. The microcentrifuge tubes were vortexed for $10 \mathrm{~min}$ to obtain the crude extract which

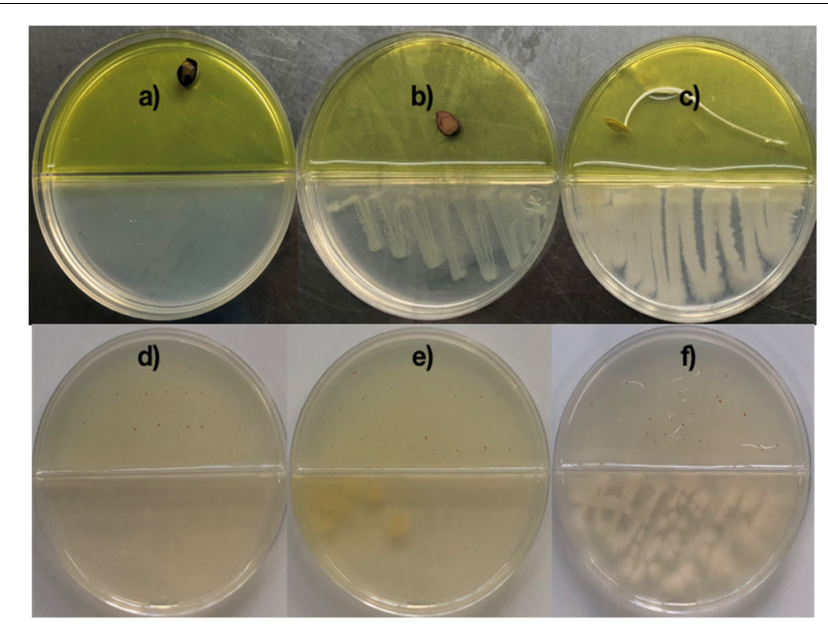

FIGURE 1 | Co-cultivation of Bacillus sp. MH778713 and Prosopis laevigata/Arabidopsis thaliana in partitioned Petri dish in the dark at $28^{\circ} \mathrm{C}$ for germination assay. Pictures were taken after 72 and $120 \mathrm{~h}$ for Prosopis and Arabidopsis, but germination was observed after 24 and $72 \mathrm{~h}$, respectively. Prosopis laevigata seeds were imbibed $72 \mathrm{~h}$ on an aqueous agar plate containing $2500 \mathrm{mg} \mathrm{L}^{-1}$ of $\mathrm{Cr}(\mathrm{VI})$ while exposed to volatiles released by Escherichia coli BL21 (DE3) as a negative control (b), Bacillus sp. MH778713 (c) or nothing (negative control) (a). Similarly, Arabidopsis thaliana seeds were imbibed $120 \mathrm{~h}$ on an aqueous agar plate containing $100 \mathrm{mg} \mathrm{L}^{-1} \mathrm{Cr}(\mathrm{VI})$ while exposed to volatiles released by E. coli BL21 (DE3) (e), Bacillus sp.

$\mathrm{MH} 778713$ (f) or nothing (d). Seed germination assays were done in quintuplet; each experiment was repeated at least three times.

was centrifuged at $13000 \mathrm{rpm}(15865 \mathrm{~g})$ for $5 \mathrm{~min}$ twice, the supernatant was collected for the gas chromatography-mass spectrometry (GC-MS) analysis. The metabolites extracted from co-cultivation of Bacillus sp. MH778713-Prosopis seed and cultures of Bacillus alone were analyzed by GC-MS. Similarly, E. coli BL21 DE3 was grown for $24 \mathrm{~h}$ in sealed partitioned Petri dishes with Prosopis seed for metabolites extraction with benzene as a negative control. GC/SM analysis was performed using Agilent 7820A Gas Chromatograph system (Santa Clara, CA, United States) with a HP-5ms column (30 m length, $0.25 \mathrm{~mm}$ i.d., $0.25 \mu \mathrm{m}$ film thickness). The initial oven temperature was set at $40^{\circ} \mathrm{C}$ and kept for $5 \mathrm{~min}$, then ramped up at a rate of $15^{\circ} \mathrm{C} / \mathrm{min}$ to $240^{\circ} \mathrm{C}$, and held $6.667 \mathrm{~min}$, for a total run time of $25 \mathrm{~min}$. The carrier gas was helium at $1.2 \mathrm{ml} / \mathrm{min}$ rate. The Agilent 5975C Gas Chromatograph/Mass Selective Detector (Santa Clara, CA, United States) was operated in the electron ionization mode at $70 \mathrm{eV}$, a source temperature of $220^{\circ} \mathrm{C}$, with a continuous scan from $\mathrm{m} / \mathrm{z} 50$ to 500 . The constituents of benzene extracts were identified by comparing the fragmentation patterns in mass spectra with those of the NIST08.L library and published mass spectra. To confirm the presence of 2,4-ditert-butylphenol, heneicosane, tetracosane, and hentriacontane in the benzene extracts, the retention time of the GC peaks of reference compounds run under identical conditions and mass spectra was also compared. Each sample was run in triplicate. Most abundant compounds that we identified as being emitted by Bacillus sp. MH778713 were 
tested individually for their ability to promote seed germination under Cr-stress.

\section{Promotion of Seed Germination and Seedling Growth of Prosopis laevigata and Arabidopsis thaliana by 2,4-Di-Tert-Butylphenol, Heneicosane, Hentriacontane, and Tetracosane Under Cr-Stress}

To evaluate the ability of 2,4-Di-tert-butyl phenol (CAS\# 96-764), heneicosane (CAS\# 629-94-7), hentriacontane (CAS\# 630-046), and tetracosane (CAS\# 646-31-1) to break seed dormancy of Cr-stressed seeds; partitioned Petri dish experiments were performed as described above. A stock solution of each compound was prepared using benzene as a solvent. Two initial dosages of each compound were assayed, 50 and $500 \mu \mathrm{g}$, considering the concentrations reported in the literature as an optimal (0.01-100 $\mu \mathrm{g})$ for plant-growth induction in partitioned Petri dish experiments (Fincheira and Quiroz, 2018). Thus, 6 or $60 \mu \mathrm{l}$ of each stock solution was inoculated on Yeast extract Mannitol Agar (YMA) medium on one side of the partitioned plate and Prosopis or Arabidopsis seed was placed onto the Crwater agar [ 2500 or $100 \mathrm{mg} \mathrm{L}^{-1} \mathrm{Cr}(\mathrm{VI}), 0.75 \% \mathrm{w} / \mathrm{v}$ agar] medium on the other side of the plate to evaluate seed germination. Partitioned Petri plates were incubated at $28^{\circ} \mathrm{C}$ for 24 and $72 \mathrm{~h}$ in the darkness for Prosopis and Arabidopsis germination; although pictures for figures were taken after 72 and $120 \mathrm{~h}$, respectively. In the same way, E. coli BL21 (DE3) or benzene $(6 \mu \mathrm{l})$ was inoculated on the YMA medium on one side of the partitioned plate as negative control while Bacillus sp. MH778713 was inoculated as a positive control. After $72 \mathrm{~h}$ of incubation, the growth parameters of Prosopis seedlings were evaluated to determine which compound was more effective (Figure 5). The promotion of seed germination was done in quintuplet; each experiment was repeated at least three times. Finally, 0.05, 0.5 , and $5 \mu \mathrm{g}$ of each compound was also evaluated for the germination assays.

\section{Growth Promotion of Prosopis Seedling by 2,4-Di-Tert-Butylphenol, Heneicosane, Hentriacontane, Tetracosane, and Bacillus sp. MH778713}

Partitioned Petri plates were prepared as described above with YMA and water-agar $(0.75 \% \mathrm{w} / \mathrm{v})$ medium. No chromium was added to the seed side of the Petri dish to let seedling growth normally under this condition. On the side of the plate containing YMA medium $6 \mu \mathrm{l}$ of solvent alone (benzene), $50 \mu \mathrm{g}$ of 2,4di-tert-butyl phenol, heneicosane, hentriacontane, or tetracosane was added to evaluate Prosopis seedling growth promotion. Furthermore, partitioned Petri plates with $10 \mu \mathrm{l}$ of Bacillus sp. MH778713 $\left(1 \times 10^{10} \mathrm{CFU} / \mathrm{ml}\right)$ on YMA medium and Prosopis seeds on the water-agar medium were included as a positive control.

\section{Statistical Analysis}

The statistical analysis of seedling growth parameters was performed using Sigma Plot (Handel Scientific Software). Data were analyzed globally by ANOVA single factor, and significant treatment effects were determined by the TukeyKramer Post Hoc test.

\section{RESULTS}

\section{Volatiles Emitted by Bacillus sp. MH778713 Break Seed Dormancy}

Chromium is highly toxic to plants and harmful to their growth and development. To determine the minimal amount of chromium (VI) that prevent seed germination, surface-sterilized seeds of Prosopis laevigata and Arabidopsis thaliana were placed onto water-agar plates supplemented with $100,200,300, \ldots$ up to $2500 \mathrm{mg} \mathrm{L}^{-1}$ of $\mathrm{K}_{2} \mathrm{CrO}_{4}$ for germination assays of Prosopis and $10,20,30, \ldots$ up to $100 \mathrm{mg} \mathrm{L}^{-1}$ for Arabidopsis. We found out that 100 and $2500 \mathrm{mg} \mathrm{L}^{-1}$ of $\mathrm{Cr}(\mathrm{VI})$ precluded seed germination of A. thaliana and P. laevigata, confirming chromium phytotoxic effects. To assess the ability of Bacillus sp. MH778713 to produce volatiles and promote germination of seeds exposed to Cr(VI), co-cultivations of Bacillus sp. MH778713 and Prosopis laevigata/Arabidopsis thaliana in partitioned Petri dish were carried out over 3 and 5 days, respectively. Two types of agar-media were used in each partitioned Petri plate, YMAgar medium on bacteria's side and Water-Agar added with chromium on the seed side. The yellow color of the medium on the Prosopis seed's side was caused by the high chromium concentration (Figures 1a-c). Partitioned Petri plates prevent any physical contact between bacteria and seeds or diffusion of non-volatile metabolites through the medium. Thus, any stimulating effect of Bacillus sp. MH778713 on seed germination can be attributed to the volatiles emitted by the bacterium. Our results showed that in the presence of Bacillus sp. MH778713, $P$. laevigata seeds on Cr-agar plates germinated in $24 \mathrm{~h}$ of co-cultivation and showed an efficient seedling development until $72 \mathrm{~h}$ (Figure 1c), while the negative control (seeds nonexposed to Bacillus VOCs) were unable to germinate in presence of chromium (Figure 1a). Similar results were observed with Arabidopsis thaliana seeds (Figures 1d,f), suggesting that Bacillus sp. MH778713 produces volatiles that promote germination and seedling growth under chromium phytotoxic conditions. Escherichia coli BL21(DE3), like any living organism, produces volatiles and was used as a second negative control (Figures 1b,e). Under chromium stress, neither Prosopis nor Arabidopsis seeds germinated when they were exposed to volatiles emitted by E. coli (Figures 1b,e). These results indicate that airborne signals emitted by Bacillus sp. MH778713 trigger seed dormancybreaking on the partitioned Petri dish experiments. Since bacteria growing in rich media can use amino acids as a carbon source releasing ammonia, thus alkalinizing the medium, the $\mathrm{pH}$ of Bacillus and E. coli cultures was measured. Both bacteria were cultivated on YMA plates with an initial $\mathrm{pH}$ of 6.8 , after $72 \mathrm{~h}$ the $\mathrm{pH}$ of Bacillus and E. coli cultures were 8 and 5.5, respectively. 
These results indicate that $E$. coli can be producing organic acids responsible of the $\mathrm{pH}$ drop.

\section{Long-Chain Alkanes and 2,4-Di-Tert-Butylphenol Were the Most Abundant Metabolites Produced by Bacillus sp. MH778713}

To determine the metabolites emitted by Bacillus sp. MH778713, bacterial cultures like those described in Figure 1c were carried out taking samples from the Petri plates at 24 and $48 \mathrm{~h}$. Benzene was used for extracting compounds produced by the Bacillus cultures and metabolites profile was determined using GC-MS analysis as described in section "Materials and Methods." Nature of metabolites produced by Bacillus sp. MH778713 include alcohols, alkanes, alkenes, esters, ketones, amide, and fatty acids (Figure 2). A total of 29 compounds were identified, 18 of them were absent at $48 \mathrm{~h}$ of culture while eleven of them were present both at 24 and $48 \mathrm{~h}$. The most abundant compounds produced at $24 \mathrm{~h}$ of culture were heneicosane, 2,4-di-tert-butylphenol, eicosane, hentriacontane, octadecane, octacosane, and $n$-octadecyl ester-heptafluorobutyric acid (Figure 2). To determine if Prosopis seeds were also producing volatiles during germination ( $24 \mathrm{~h}$ of incubation), the metabolite profile of Bacillus growing alone (without seed) in a partitioned Petri plate was determined. As shown in Figure 2, the profile of Bacillus with and without seed were comparable, except for 2-bromotetradecane, $n$-octadecyl esterheptafluorobutyric acid, nonadecane, hexacosane, 7,9-Di-tertbutyl-1-oxaspiro(4,5)deca-6,9-diene-2,8-dione, 1-docosene, and 11-(1-ethylpropyl)-heneicosane that were produced only when Prosopis seed was present. Since culture medium and E. coli produce volatiles, the profile of $E$. coli growing in YMA was determined in a partitioned plate in the presence of Prosopis seed. No peaks related to heneicosane, 2,4-di-tertbutylphenol, eicosane, hentriacontane, octadecane, octacosane, or heptadecane were found, indicating that long-chain alkanes were certainly produced by Bacillus sp. MH778713. The chromatographic profiles of metabolites from Bacillus sp. MH778713 and E. coli BL21(DE3) at $24 \mathrm{~h}$ of incubation are shown in the Supplementary Figures S2, S3. The number of compounds produced by Bacillus sp. MH778713 was much higher than those produced by E. coli. Heneicosane, 2,4-di-tertbutylphenol, hentriacontane and tetracosane standards were used to quantify the amount produced by Bacillus sp. MH778713 in Petri plate, finding out that it ranged from 0.01 to $0.07 \mu \mathrm{g}$. The identity of heneicosane, 2,4-di-tert-butylphenol, and tetracosane produced by Bacillus sp. MH778713 was confirmed by comparing Kovats retention indices (KIs) with KI from pheromone data base (Supplementary Table S1). To determine if heneicosane, 2,4-ditert-butylphenol, hentriacontane, and tetracosane were present as volatiles in the headspace of the Bacillus sp. MH778713 culture a partitioned plate-experiment was carried out incubating an absorbent material (zeolites) on one side of the plate and Bacillus

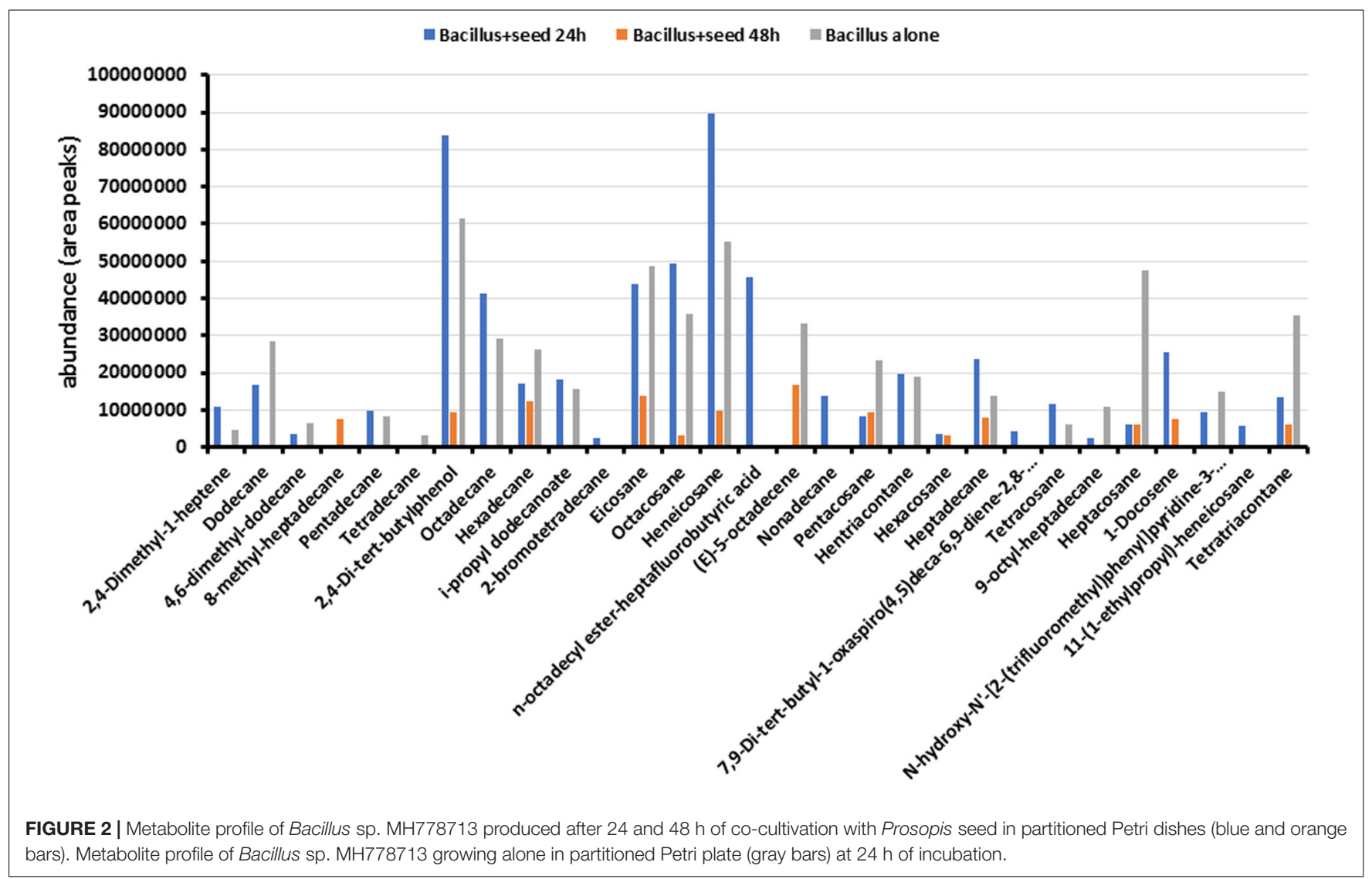


culture on the other. After $24 \mathrm{~h}$ of incubation, volatiles from absorbent material were extracted with benzene and analyzed by GC-MS. None of four compounds was detected in the headspace of the cultures by this method used.

\section{Heneicosane, 2,4-Di-Tert-Butylphenol, Hentriacontane, and Tetracosane Trigger Seed Dormancy-Breaking}

2,4-di-tert-butyl phenol, heneicosane, hentriacontane, and tetracosane were selected to explore their ability to induce seed dormancy-breaking. 2,4-di-tert-butylphenol was chosen because it is a well-known antioxidant and antifungal VOC produced by Shewanella algae YM17, Trichoderma harzianum T-E5, and Arthrobacter agilis UMCV2. Since our Bacillus sp. MH778713 produced alkanes range from $\mathrm{C} 16$ to $\mathrm{C} 34$ atoms, heneicosane $\left(\mathrm{C}_{21} \mathrm{H}_{44}\right)$ was chosen as a representative compound of alkanes of 20 carbons and hentriacontane $\left(\mathrm{C}_{31} \mathrm{H}_{64}\right)$ as a representative of alkanes of 30 carbons. Moreover, tetracosane $\left(\mathrm{C}_{24} \mathrm{H}_{50}\right)$ was included in the assay to test if alike alkanes behave similarly $\left(\mathrm{C}_{21} \mathrm{H}_{44}\right.$ and $\left.\mathrm{C}_{24} \mathrm{H}_{50}\right)$. Considering the VOCs concentration reported in the literature as optimal for plant-growth induction in partitioned Petri dish experiments $(0.01-100 \mu \mathrm{g})$, we decided to test a moderate $(50 \mu \mathrm{g})$ and high $(500 \mu \mathrm{g})$ dosage of 2,4-di-tert-butyl phenol, heneicosane, hentriacontane, and tetracosane. All compounds induced seed germination in the presence of chromium and no difference in the stimulating effect on seed germination was observed at 50 and $500 \mu \mathrm{g}$ dosage. The high $(500 \mu \mathrm{g})$ dosage of 2,4-di-tert-butyl phenol, heneicosane, hentriacontane, and tetracosane did not show any phytotoxic effects on the seed germination assay of Prosopis. Representative pictures of seed germination experiments using $50 \mu \mathrm{g}$ of 2,4-di-tert-butyl phenol, heneicosane, hentriacontane, and tetracosane are shown in Figure 3. For each condition tested, five Prosopis laevigata seeds were assayed, one per plate, over 3 days of laboratory conditions. Each seed was placed on a water-agar medium added with $2500 \mathrm{mg} \mathrm{L}^{-1}$ of chromium (VI) and 2,4-di-tert-butyl phenol, heneicosane, hentriacontane, tetracosane or benzene were inoculated on YM-agar side of the partitioned Petri dish. The negative control, benzene, was unable to induce seed germination (Figure 3a) while all assessed compounds triggered seed dormancy-breaking (Figures $\mathbf{3 b} \mathbf{b}-\mathbf{e}$ ). Since all stock solutions were prepared using benzene as a solvent, benzene was also tested as a growth inducer but failed to induce seed dormancy-breaking (Figure 3a). Similarly, pure compounds were tested on A. thaliana seeds subjected to $100 \mathrm{mg}$ $\mathrm{L}^{-1}$ of chromium (Figure 4). Benzene failed to break seed dormancy of $A$. thaliana (Figure 4a), while $50 \mu \mathrm{g}$ of tetracosane, hentriacontane, heneicosane, and 2,4-di-tert-butyl phenol induced 96, 44, 72, and 56\% of seed germination (Figures $\mathbf{4 b - e )}$ ). Lower concentrations $(0.05,0.5$, and $5 \mu$ g per plate) of each pure compound were tested for their ability to break the dormancy of Prosopis seeds under chromium stress. Only the dosage of $5 \mu \mathrm{g}$ was able to break seed dormancy while 0.05 and $0.5 \mu \mathrm{g}$ was not (Supplementary Figure S1).

The growth stimulation of Prosopis laevigata seedlings subjected to chromium toxicity was determined (Figure 5). The

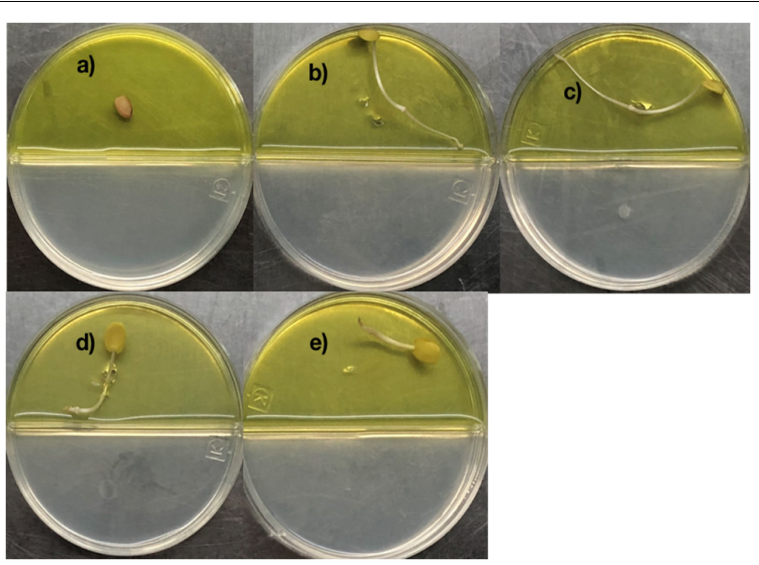

FIGURE 3 | Promotion of seed germination by tetracosane, heneicosane, hentriacontane and 2,4-Di-tert-butylphenol under Cr-stress. Prosopis laevigata seeds were imbibed $72 \mathrm{~h}$ at $28^{\circ} \mathrm{C}$ in the dark on aqueous agar plate containing $2500 \mathrm{mg} \mathrm{L}^{-1}$ of chromium(VI) while exposed to vapor of benzene as negative control (a), tetracosane (b), heneicosane (c), hentriacontane (d), and 2,4-Di-tert-butyl phenol (e). Promotion of seed germination was done in quintuplet using $50 \mu \mathrm{g}$ of the pure compound; experiments were repeated at least three times.

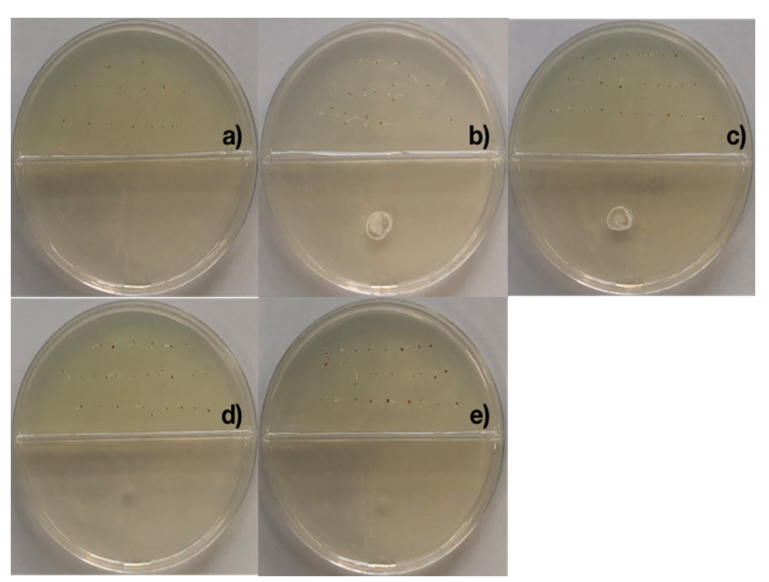

FIGURE 4 | Promotion of seed germination by tetracosane, heneicosane, hentriacontane and 2,4-Di-tert-butyl phenol under Cr-stress. Arabidopsis thaliana seeds were imbibed $120 \mathrm{~h}$ at $28^{\circ} \mathrm{C}$ in the dark on aqueous agar plate containing $100 \mathrm{mg} \mathrm{L}^{-1}$ of chromium(VI) while exposed to vapor of benzene as negative control (a), tetracosane (b), hentriacontane (c), heneicosane (d), and 2,4-Di-tert-butyl phenol (e). Promotion of seed germination was done using 25 seeds per plate, each plate added with $50 \mu \mathrm{g}$ of the pure compound; experiments were repeated at least three times.

root length obtained with heneicosane $\left(\mathrm{C}_{21} \mathrm{H}_{44}\right)$, tetracosane $\left(\mathrm{C}_{24} \mathrm{H}_{50}\right)$ and hentriacontane $\left(\mathrm{C}_{31} \mathrm{H}_{64}\right)$ were significantly higher than those of 2,4-di-tert-butylphenol but lower than those obtained with volatile emitted by Bacillus sp. MH778713. For the shoot length stimulation, heneicosane $\left(\mathrm{C}_{21} \mathrm{H}_{44}\right)$ and tetracosane $\left(\mathrm{C}_{24} \mathrm{H}_{50}\right)$ were as good inducers as volatiles released by Bacillus sp. MH778713. The growth promotion of Prosopis seedlings by long-chain alkanes and Bacillus sp. MH778713 volatiles was also evaluated without chromium stress (Figure 6). 


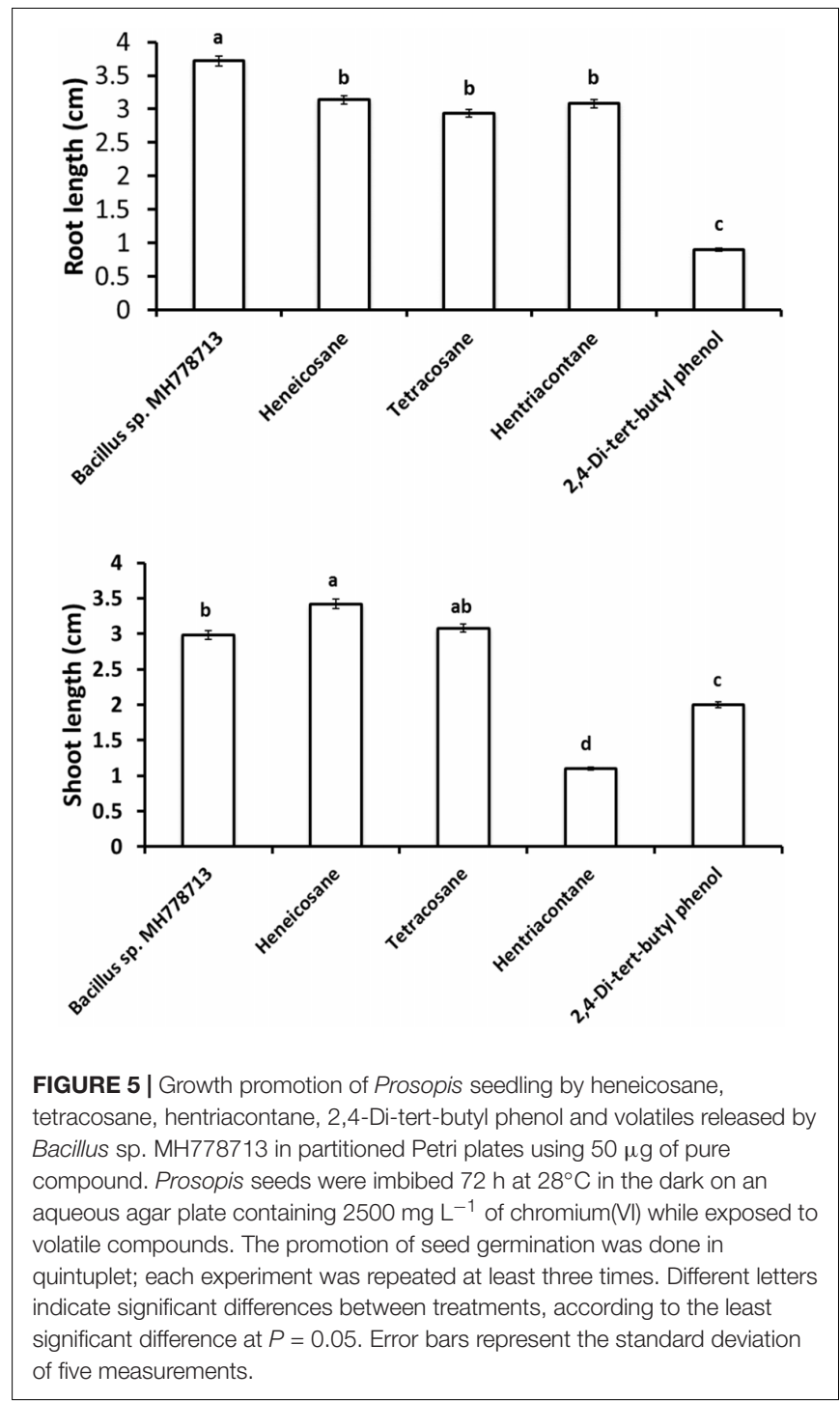

Root and shoot length of seedling exposed to Bacillus sp. MH778713 volatiles, tetracosane, heneicosane, hentriacontane or 2,4-di-tert-butylphenol were greater than those of the seedling control (seeds without any volatile). These results together indicate that heneicosane, 2,4-di-tert-butylphenol, hentriacontane, and tetracosane are growth inducers of Prosopis laevigata seedlings and allow seeds to overcome phytotoxicity imposed by chromium (VI).

\section{DISCUSSION}

In this work, we established the ability of Bacillus sp. MH778713 to produce volatiles which in turn triggered the breaking of seed dormancy under chromium stress condition. Plant growthpromoting rhizobacteria release a blend of volatile compounds such as 2,3-butanediol, 1,3-propanediol, indole, acetoin, 2nonanone, 2-undecanone, 2-tridecanone, hexadecane, and other hydrocarbons, ketones, alcohols, terpenes, acids, and sulfurs
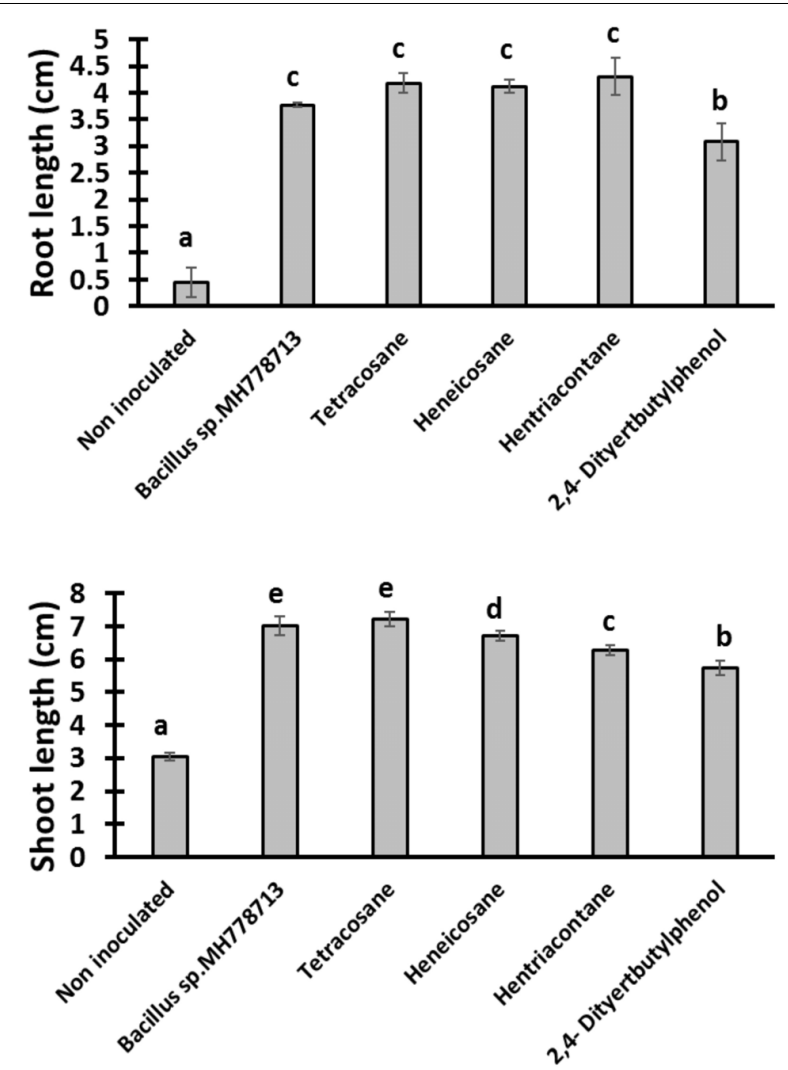

FIGURE 6 | Growth promotion of Prosopis seedling by heneicosane, tetracosane, hentriacontane, 2,4-Di-tert-butyl phenol and volatiles released by Bacillus sp. MH778713 in partitioned Petri plates without chromium using $50 \mu \mathrm{g}$ of pure compound. Prosopis seeds were imbibed $72 \mathrm{~h}$ at $28^{\circ} \mathrm{C}$ in the dark on aqueous agar plate while exposed to volatile compounds. The promotion of seed germination was done in quintuplet; each experiment was repeated at least three times. Different letters indicate significant differences between treatments, according to the least significant difference at $P=0.05$. Error bars represent the standard deviation of five measurements.

that can stimulate plant growth, control plant pathogens, and induce systemic disease resistance (Ryu et al., 2003; Audrain et al., 2015; Fincheira et al., 2017). Different environmental signals can induce or preclude seed germination. A dormancy state can prevent imbibed viable seeds from germinating under apparently favorable conditions as an adaptive strategy (Arc et al., 2013; Nishimura et al., 2018). Heavy metals, for example, trigger signals (increasing $\mathrm{ABA}$ concentrations) that preclude seed germination inducing a dormancy state. Although seed coat provides protection, some metals can permeate into the seed before germination or diffuse into the embryo upon seed-coat cracking leading to alterations into nitrogen and carbohydrate metabolism, water uptake, oxidative stress, and seed germination (Kranner and Colville, 2011; Yildız and Terzi, 2016; Kaszycki et al., 2018). Elevated $\mathrm{Cr}(\mathrm{VI})$ concentrations (75-100 $\mathrm{mg} \mathrm{kg}^{-1}$ soil) inhibit seed germination, reduce chlorophyll contents and affect most of the growth parameters of biofuel plant species (Amin et al., 2019). In this work, $2500 \mathrm{mg} \mathrm{L}^{-1}$ of $\mathrm{Cr}(\mathrm{VI})$ $\left(\sim 1980 \mathrm{mg} \mathrm{kg}^{-1}\right.$ soil) was required to prevent Prosopis laevigata 
germination, highlighting the heavy metal tolerance of Prosopis. The high $\mathrm{Cr}$ concentration tested $\left(2500 \mathrm{mg} \mathrm{L}^{-1}\right)$ is 19 -fold higher than those found in polluted soils (Amin et al., 2019); showing the bioremediation potential of using $P$. laevigata in combination with Bacillus sp. MH778713 for soil restoration of sites contaminated with Cr. Since the Cr-tolerant Bacillus sp. MH778713 is also highly tolerant to aluminum (up to $10000 \mathrm{mg}$ $\mathrm{L}^{-1}$ ), it could be expected that the system P. laevigata-Bacillus sp. MH778713 could also work in aluminum polluted sites (Ramírez et al., 2019). The deleterious and signaling role of ROS in plants is well documented, thus ROS fine-tuning plays a key role in seed physiology (Bailly et al., 2008). In our experiments, elevated ROS generated by seeds subjected to $\mathrm{Cr}$ stress would likely prevent seed germination by repressing hormonal signaling pathways involved in the alleviation of dormancy. However, further analysis will be required to elucidate the mechanisms of $\mathrm{Cr}(\mathrm{VI})$ preventing seed germination.

Volatiles emitted by Bacillus sp. MH778713 allowed P. laevigata seeds to overcome $\mathrm{Cr}(\mathrm{VI})$ toxicity, breaking seed dormancy while developing healthy sprouts (Figure 1). Since the medium of Bacillus cultures was alkalinized during germination assays, probably by the release of ammonia, ammonia could probably be involved in the beneficial observed effect; nonetheless, bacterial ammonia can also cause plant growth inhibition (Weise et al., 2013). More experiments should be done to determine the contribution of ammonia in the growth of Prosopis seedlings. Although VOCs effect on seed subjected to chromium stress has not been studied yet, the promoting plant growth effect of VOCs through signaling networks of cytokinins, brassinosteroids, auxin, and gibberellins is well established (Ryu et al., 2003, 2005; Zhang et al., 2007, 2008; Lee et al., 2012; Park et al., 2013). Of most abundant volatiles produced by Bacillus sp. MH778713 at $24 \mathrm{~h}$ in partitioned Petri dishes, four, heneicosane, hentriacontane, tetracosane, and 2,4-di-tert-butylphenol, were tested as pure compounds and found to break the dormancy of Prosopis seeds subjected to $\mathrm{Cr}(\mathrm{VI})$ phytotoxicity (Figures 3, 4). Although the mechanism of long-chain bacterial compounds underlying the observed seed germination under Cr-stress remains to be elucidated, the ability of long-chain hydrocarbons to elicit plant defense against pathogens in Arabidopsis is already known. Tridecane and hexadecane significantly up-regulate pathogenesis-related gene 1 (PR1) for salicylic acid signaling decreasing sensitivity to biotrophic pathogen infection (Lee et al., 2012; Park et al., 2013).

Bacillus sp. MH778713 was found to produce long-chain hydrocarbons such as C34, C31, C28, C25, C21, and C20 alkanes that likely are VOCs influencing the seed (Figure 2). However, bacterial volatile compounds are considered odorous molecules with low molecular weight $(<300 \mathrm{Da})$ and high vapor pressure $\left(0.01 \mathrm{kPa}\right.$ at $\left.20^{\circ} \mathrm{C}\right)$ that easily become vapors (Audrain et al., 2015). The two most abundant volatiles released by PGPR with the characteristics described above is acetoin and 2,3-butanediol. Indeed, Bacillus subtilis GB03 and Bacillus amyloliquefaciens IN937a produce more than thirty low molecular-weight bacterial volatiles (Lee et al., 2012). Nonetheless, other studies have found high molecular weight VOCs produced by PGPR. Pseudomonas brassicacearum and Pseudomonas putida for example, release long-chain hydrocarbons like triacontane $\left(\mathrm{C}_{30} \mathrm{H}_{62}\right)$, octacosane $\left(\mathrm{C}_{28} \mathrm{H}_{58}\right)$, heptacosane $\left(\mathrm{C}_{27} \mathrm{H}_{56}\right)$, and heneicosane $\left(\mathrm{C}_{21} \mathrm{H}_{44}\right)$ with molecular weight as high as $422 \mathrm{~g} / \mathrm{mol}$ and vapor pressure as low as $3.6 \times 10^{-12} \mathrm{kPa}$ and still being detected in the headspace of agar slant tubes by solid-phase micro-extraction (SPME) method (Giorgio et al., 2015). So, finding long-chain alkanes in our results was not surprising since the quantity and identity of volatile blends produced by rhizobacteria vary significantly among species (Ryu et al., 2003; Lee et al., 2012; Farag et al., 2013; Fincheira et al., 2017; Giorgio et al., 2015). The release of long-chain alkanes (C31, C28, C27, and C21) by rhizobacteria isolated from common bean was previously reported (Giorgio et al., 2015), but the biological role of long-chain alkanes was not further assessed. Although the method used in this work failed to detect long-chain alkanes in the headspace of Bacillus cultures, and solid-phase micro-extraction should be used instead, the results presented herein provide evidence that Bacillus sp. MH778713 emits long-chain bacterial compounds (heneicosane, hentriacontane, tetracosane) that can prime signaling pathways related to abiotic stress tolerance to chromium. From the germination assays with pure compounds, it was suggested that 2,4-di-tert-butyl phenol, heneicosane, hentriacontane, and tetracosane can be volatiles but a pre-concentration system like solid-phase micro-extraction will be required to detect them in the headspace of Bacillus sp. MH778713 cultures (Povolo and Contarini, 2003; Zscheppank et al., 2014). Further works will be required to decipher the molecular targets within seeds sensing the metabolites signals emitted by Bacillus in order to elucidate a potential mechanism by which these compounds break seed dormancy.

\section{CONCLUSION}

Overall, the results provide new evidence that C31, C24, C21 hydrocarbon, hentriacontane, tetracosane, and heneicosane emitted from Bacillus sp. MH778713 can help seeds to overcome chromium toxicity that otherwise prevent seed germination.

\section{DATA AVAILABILITY STATEMENT}

All datasets generated for this study are included in the article/Supplementary Material.

\section{AUTHOR CONTRIBUTIONS}

VR, J-AM, and AB conceived, designed, and directed the project, contributed to the interpretation of the results, and designed the figures. VR worked out almost all the technical details, contributed to sample preparation, carried out the experiments, and performed the numerical calculations for the suggested experiments. VR, LC, JM-R, and RP participated in the acquisition of the data. RP, JM-R, and AB supervised the work. $\mathrm{VR}, \mathrm{LC}$, and RP manufactured the samples and performed the GC-MS analysis. AB and J-AM took the lead in the writing of the manuscript. All authors provided critical feedback, helped to 
shape the research, analysis, and manuscript discussed the results and contributed to the final version of the manuscript.

\section{FUNDING}

This work was supported by VIEP-BUAP-2018 ID00483 and CONACyT 252847 Research Grant. VR is grateful for grant number 273291 from CONACyT.

\section{SUPPLEMENTARY MATERIAL}

The Supplementary Material for this article can be found online at: https://www.frontiersin.org/articles/10.3389/fmicb. 2020.00741/full\#supplementary-material

\section{REFERENCES}

Akinci, I., and Akinci, S. (2010). Effect of chromium toxicity on germination and early seedling growth in melon (Cucumis melo L.). Afr. J. Biotechnol. 929, 4589-4594.

Aldrich, M. V., Gardea-Torresdey, J. L., Peralta-Videa, J. R., and Parsons, J. G. (2003). Uptake and reduction of $\mathrm{Cr}$ (VI) to $\mathrm{Cr}$ (III) by mesquite (Prosopis spp.): chromate-plant interaction in hydroponics and solid media studied using XAS. Environ. Sci. Technol. 37, 1859-1864. doi: 10.1021/es0208916

Aldrich, M. V., Peralta-Videa, J. R., Parsons, J. G., and Gardea-Torresdey, J. L. (2007). Examination of arsenic (III) and (V) uptake by the desert plant species mesquite (Prosopis spp.) using X-ray absorption spectroscopy. Sci. Total Environ. 379, 249-255. doi: 10.1016/j.scitotenv.2006.08.053

Amin, H., Ahmed, A. B., Abbasi, M. S., Amin, F., Jahangir, T. M., and Soomro, N. U. (2019). Evaluation of chromium phyto-toxicity, phyto-tolerance, and phyto-accumulation using biofuel plants for effective phytoremediation. Int. J. Phytoremediation. 21, 352-363. doi: 10.1080/15226514.2018. 1524837

Arc, E., Sechet, J., Corbineau, F., Rajjou, L., and Marion-Poll, A. (2013). ABA crosstalk with ethylene and nitric oxide in seed dormancy and germination. Front. Plant. Sci. 4:63. doi: 10.3389/fpls.2013.00063

Audrain, B., Farag, M. A., Ryu, C. M., and Ghigo, J. M. (2015). Role of bacterial volatile compounds in bacterial biology. FEMS Microbiol. Rev. 39, 222-233. doi: 10.1093/femsre/fuu013

Backer, R., Rokem, J. S., Ilangumaran, G., Lamont, J., Praslickova, D., Ricci, E., et al. (2018). Plant growth-promoting rhizobacteria: context, mechanisms of action, and roadmap to commercialization of biostimulants for sustainable agriculture. Front. Plant Sci. 9:1473. doi: 10.3389/fpls.2018.01473

Bailly, C., El-Maarouf-Bouteau, H., and Corbineau, F. (2008). From intracellular signaling networks to cell death: the dual role of reactive oxygen species in seed physiology. C. R. Biol. 331, 806-814. doi: 10.1016/j.crvi.2008. 07.022

Bitas, V., Kim, H., Bennett, J. W., and Kang, S. (2013). Sniffing on microbes: diverse roles of microbial volatile organic compounds in plant health. Mol. Plant Microbe Interac. 26, 835-843. doi: 10.1094/mpmi-10-12-0249-cr

Bruno, L. B., Karthik, C., Ma, Y., Kadirvelu, K., Freitas, H., and Rajkumar, M. (2020). Amelioration of chromium and heat stresses in Sorghum bicolor by $\mathrm{Cr}^{6+}$ reducing thermotolerant plant growth promoting bacteria. Chemosphere 244:125521. doi: 10.1016/j.chemosphere.2019.125521

Bücker-Neto, L., Paiva, A. L. S., Machado, R. D., Arenhart, R. A., and MargisPinheiro, M. (2017). Interactions between plant hormones and heavy metals responses. Genet. Mol. Biol. 40, 373-386. doi: 10.1590/1678-4685-gmb-20160087

Din, B. U., Amna Rafique, M., Javed, M. T., Kamran, M. A., Mehmood, S., Khan, M., et al. (2020). Assisted phytoremediation of chromium spiked soils by Sesbania Sesban in association with Bacillus xiamenensis PM14: a biochemical analysis. Plant Physiol. Biochem. 146, 249-258. doi: 10.1016/j.plaphy.2019. 11.010
FIGURE S1 | Promotion of seed germination by $5 \mu \mathrm{g}$ of tetracosane, heneicosane, hentriacontane and 2,4-Di-tert-butyl phenol under Cr-stress. Prosopis laevigata seeds were imbibed $72 \mathrm{~h}$ at $28^{\circ} \mathrm{C}$ in the dark on aqueous agar plate containing $2500 \mathrm{mg} \mathrm{L}^{-1}$ of chromium(VI) while exposed to vapor of benzene as negative control (a), Bacillus sp. MH778713 (b), tetracosane (c), heneicosane (d), hentriacontane (e), and 2,4-Di-tert-butyl phenol (f). Promotion of seed germination was done in quintuplet using $5 \mu \mathrm{g}$ of the pure compound; experiments were repeated at least three times.

FIGURE S2 | Metabolite profile of Bacillus sp. MH778713 grown alone at $24 \mathrm{~h}$ of incubation in YMA sealed plate.

FIGURE S3 | Metabolite profile of Escherichia coli BL21 (DE3) grown in co-culture with Prosopis seed at $24 \mathrm{~h}$ of incubation in YMA sealed plate.

TABLE S1 | Kovats retention indices. RT, retention time; KI exp., experimental Kovats index; KI Pherobase, Kovats index from pheromone database. NA, not available.

Dube, B. K., Tewari, K., Chatterjee, J., and Chatterjee, C. (2003). Excess chromium alters uptake and translocation of certain nutrients in citrullus. Chemosphere 53 , 1147-1153. doi: 10.1016/s0045-6535(03)00570-8

Farag, M. A., Zhang, H., Ryu, C. M. (2013). Dynamic chemical communication between plants and bacteria through airborne signals: induced resistance by bacterial volatiles. J. Chem. Ecol. 39, 1007-1018. doi: 10.1007/s10886-013-03179

Fincheira, P., Parada, M., and Quiroz, A. (2017). Volatile organic compounds stimulate plant growing and seed germination of Lactuca sativa. J. Soil Sci. Plant Nutr. 17, 853-867. doi: 10.4067/s0718-95162017000400002

Fincheira, P., and Quiroz, A. (2018). Microbial volatiles as plant growth inducers. Microbiol. Res. 208, 63-75. doi: 10.1016/j.micres.2018.01.002

Giorgio, A., De Stradis, A., Lo Cantore, P., and Iacobellis, N. S. (2015). Biocide effects of volatile organic compounds produced by potential biocontrol rhizobacteria on Sclerotinia sclerotiorum. Front. Microbiol. 6:1056. doi: 10.3389/ fmicb.2015.01056

Graeber, K., Nakabayashi, K., Miatton, E., Leubner-Metzger, G., and Soppe, W. J. (2012). Molecular mechanisms of seed dormancy. Plant Cell Environ. 35, 1769-1786. doi: 10.1111/j.1365-3040.2012.02542.x

Gutierrez-Luna, F. M., López-Bucio, J., Altamirano-Hernández, J., ValenciaCantero, E., Reyes de la Cruz, H., and Macías-Rodríguez, L. (2010). Plant growth-promoting rhizobacteria modulate root-system architecture in Arabidopsis thaliana through volatile organic compound emission. Symbiosis 51, 75-83. doi: 10.1007/s13199-010-0066-2

Jain, R., Singh, S. P., Singh, A., Singh, S., Tripathi, P., Chandra, A., et al. (2016). Study on physio-biochemical attributes and metallothionein gene expression affected by chromium(VI) in sugarcane (Saccharum spp. hybrid). J. Environ. Biol. 37, 375-382.

Jayaram, K., and Prasad, M. N. V. (2009). Removal of Pb (II) from aqueous solution by seed powder of Prosopis juliflora D.C. J. Hazard Mater. 169, 991-997. doi: 10.1016/j.jhazmat.2009.04.048

Kaszycki, P., Dubicka-Lisowska, A., Augustynowicz, J., Piwowarczyk, B., and Wesołowski, W. (2018). Callitriche cophocarpa (water starwort) proteome under chromate stress: evidence for induction of a quinone reductase. Environ. Sci. Pollut. Res. Int. 25, 8928-8942. doi: 10.1007/s11356-017-1067-y

Kranner, I., and Colville, L. (2011). Metals and seeds: biochemical and molecular implications and their significance for seed germination. Environ. Exp. Bot. 72, 93-105. doi: 10.1016/j.envexpbot.2010.05.005

Lee, B., Farag, M. A., Park, H. B., Kloepper, J. W., Lee, S. H., and Ryu, C. M. (2012). Induced resistance by a long-chain bacterial volatile: elicitation of plant systemic defense by a C13 volatile produced by Paenibacillus polymyxa. PLoS One 7:e48744. doi: 10.1371/journal.pone.0048744

Li, Z., Gao, Y., Zhang, Y., Lin, C., Gong, D., Guan, Y., et al. (2018). Reactive oxygen species and gibberellin acid mutual induction to regulate tobacco seed germination. Front. Plant. Sci. 9:1279. doi: 10.3389/fpls.2018.01279

Liu, X. M., and Zhang, H. (2015). The effects of bacterial volatile emissions on plant abiotic stress tolerance. Front. Plant. Sci. 6:774. doi: 10.3389/fpls.2015. 00774 
Munzuroğlu, O., Zengin, F. K., and Yahyagil, Z. (2008). The abscisic acid levels of wheat (Triticum aestivum L. cv. Çakmak 79) seeds that were germinated under heavy metal $\left(\mathrm{Hg}^{++}, \mathrm{Cd}^{++}, \mathrm{Cu}^{++}\right)$stress. G.U. J. Sci. 21, 1-7.

Nishimura, N., Tsuchiya, W., Moresco, J. J., Hayashi, Y., Satoh, K., Kaiwa, N., et al. (2018). Control of seed dormancy and germination by DOG1AHG1 PP2C phosphatase complex via binding to heme. Nat. Commun. 9:2132.

Panda, S. K., and Choudhury, S. (2005). Chromium stress in plants. Braz. J. Plant Physiol. 17, 95-102. doi: 10.1590/s1677-04202005000100008

Park, H. B., Lee, B., Kloepper, J. W., and Ryu, C. M. (2013). One shot-two pathogens blocked: exposure of Arabidopsis to hexadecane, a long chain volatile organic compound, confers induced resistance against both Pectobacterium carotovorum and Pseudomonas syringae. Plant Signal. Behav. 8:e24619. doi: $10.4161 /$ psb. 24619

Povolo, M., and Contarini, G. (2003). Comparison of solid-phase microextraction and purge-and trap methods for the analysis of the volatile fraction of butter. J. Chromatogr A. 985, 117-125. doi: 10.1016/s0021-9673(02) 01395-x

Purwanti, I. F., Putri, T. P., and Kurniawan, S. B. (2017). Treatment of chromium contaminated soil using bioremediation. AIP Conf. Proc. 1903:040008. doi: $10.1063 / 1.5011527$

Ramírez, V., Baez, A., López, P., Bustillos, R., Villalobos, M. A., Carreño, R., et al. (2019). Chromium hyper-tolerant Bacillus sp. MH778713 assists phytoremediation of heavy metals by mesquite trees (Prosopis laevigata). Front. Microbiol. 10:1833. doi: 10.3389/fmicb.2019.01833

Ryu, C. M., Farag, M. A., Hu, C. H., Reddy, M. S., Kloepper, J. W., and Paré, P. W. (2004). Bacterial volatiles induce systemic resistance in Arabidopsis. Plant Physiol. 134, 1017-1026. doi: 10.1104/pp.103.026583

Ryu, C. M., Farag, M. A., Hu, C. H., Reddy, M. S., Wei, H. X., Paré, P. W., et al. (2003). Bacterial volatiles promote growth in Arabidopsis. Proc. Natl. Acad. Sci. U.S.A. 100, 4927-4932. doi: 10.1073/pnas.073084 5100

Ryu, C. M., Hu, C. H., Locy, R. D., and Kloepper, J. W. (2005). Study of mechanisms for plant growth pro-motion elicited by rhizobacteria in Arabidopsis thaliana. Plant Soil 92, 268-285.

Sharifi, R., and Ryu, C. M. (2018). Revisiting bacterial volatile-mediated plant growth promotion: lessons from the past and objectives for the future. Ann. Bot. 122, 349-358. doi: 10.1093/aob/mcy108

Shreya, D., Jinal, H. N., Kartik, V. P., and Amaresan, N. (2020). Amelioration effect of chromium-tolerant bacteria on growth, physiological properties and chromium mobilization in chickpea (Cicer arietinum) under chromium stress. Arch. Microbiol. doi: 10.1007/s00203-019-01801-1801

Vacheron, J., Desbrosses, G., Bouffaud, M. L., Touraine, B., Moënne-Loccoz, Y., Muller, D., et al. (2013). Plant growth-promoting rhizobacteria and root system functioning. Front. Plant Sci. 4:356. doi: 10.3389/fpls.2013. 00356

Vishal, B., and Kumar, P. P. (2018). Regulation of seed germination and abiotic stresses by gibberellins and abscisic acid. Front. Plant Sci. 9:838. doi: 10.3389/ fpls.2018.00838

Wang, Y., Wang, Y., Kai, W., Zhao, B., Chen, P., Sun, L., et al. (2014). Transcriptional regulation of abscisic acid signal core components during cucumber seed germination and under $\mathrm{Cu}^{2+}, \mathrm{Zn}^{2+}, \mathrm{NaCl}$ and simulated acid rain stresses. Plant Physiol. Biochem. 76, 67-76. doi: 10.1016/j.plaphy.2014.01. 003

Weise, T., Kai, M., and Piechulla, B. (2013). Bacterial ammonia causes significant plant growth inhibition. PLoS One 8:e63538. doi: 10.1371/journal.pone. 0063538

Yıldiz, M., and Terzi, H. (2016). Proteomic analysis of chromium stress and sulfur deficiency responses in leaves of two canola (Brassica napus L.) cultivars differing in $\mathrm{Cr}(\mathrm{VI})$ tolerance. Ecotoxicol. Environ. Saf. 124, 255-266. doi: 10. 1016/j.ecoenv.2015.10.023

Zhang, H., Kim, M. S., Krishnamachari, V., Payton, P., Sun, Y., Crimson, M., et al. (2007). Rhizobacterial volatile emissions regulate auxin homeostasis and cell expansion in Arabidopsis. Planta 226, 839-851. doi: 10.1007/s00425-0070530-2

Zhang, H., Kim, M. S., Sun, Y., Dowd, S. E., Shi, H., and Paré, P. W. (2008). Soil bacteria confer plant salt tolerance by tissue-specific regulation of the sodium transporter HKT1. Mol. Plant Microbe Interact. 21, 737-744. doi: 10.1094/ mpmi-21-6-0737

Zhang, H., Murzello, C., Sun, Y., Kim, M. S., Xie, X., Jeter, R. M., et al. (2010). Choline and osmotic-stress tolerance induced in Arabidopsis by the soil microbe Bacillus subtilis (GB03). Mol. Plant Microbe Interact. 23, 1097-1104.

Zscheppank, C., Wiegand, H. L., Lenzen, C., Wingender, J., and Telgheder, U. (2014). Investigation of volatile metabolites during growth of Escherichia coli and Pseudomonas aeruginosa by needle trap-GC-MS. Anal. Bioanal. Chem. 406, 6617-6628. doi: 10.1007/s00216-014-8111-2

Conflict of Interest: The authors declare that the research was conducted in the absence of any commercial or financial relationships that could be construed as a potential conflict of interest.

Copyright (C) 2020 Ramírez, Munive, Cortes, Muñoz-Rojas, Portillo and Baez. This is an open-access article distributed under the terms of the Creative Commons Attribution License (CC BY). The use, distribution or reproduction in other forums is permitted, provided the original author(s) and the copyright owner(s) are credited and that the original publication in this journal is cited, in accordance with accepted academic practice. No use, distribution or reproduction is permitted which does not comply with these terms. 